\title{
The potential role of later alteration on the inferred Mo and $U$ isotope compositions of mantle reservoirs derived from OIB lavas
}

RiCHARD GASCHNIG ${ }^{1}$, CHRISTOPHER T. REINHARD ${ }^{2}$, NOAH PLANAVSKY ${ }^{3}$, XiANGLI WANG ${ }^{3}$, DAN ASAEL ${ }^{3}$, MATT JACKSON ${ }^{4}$

${ }^{1}$ Department of Environmental, Earth and Atmospheric Sciences, University of Massachusetts Lowell, richard_gaschnig@uml.edu

${ }^{2}$ School of Earth and Atmospheric Sciences, Georgia Institute of Technology

${ }^{3}$ Department of Geology and Geophysics, Yale University

${ }^{4}$ Department of Earth Science, University of California, Santa Barbara

Mo and $U$ experience measurable and varying isotope fractionation in oceanographic settings, leading to the development of distinct isotope signatures in different types of sediments and altered ocean crust. Since these materials are ultimately subducted, and assuming that subduction has operated on multi-billion year timescales, some portions of the deep mantle that supply upwelling mantle plumes may be expected to bear these fractionated isotope signatures. Here, we explore the isotope compositions of basaltic lavas from Pitcairn, Samoa, and St. Helena, representing types localities for the EM1, EM2, and HIMU mantle end members, respectively, with the aim of fingerprinting potential recycled sedimentary sources to these lavas.

Samples from all three localities show large ranges in $\delta^{98}$ Mo values (\%o relative to NIST 3134 ), from $-0.10 \%$ (which overlaps with MORB) to $-0.85 \%$, that correlate negatively with $\mathrm{Ce} / \mathrm{Mo}$. $\delta^{238} \mathrm{U}$ values are also quite variable in all locations, ranging from -0.14 to $-0.48 \%$. While incorporation of variable amounts of $\mathrm{Fe}-\mathrm{Mn}$ oxide/hydroxide bearing sediments into the mantle source regions of these plumes might explain the variations, many of the samples, including nearly all from Pitcairn, show ${ }^{234} \mathrm{U} /{ }^{238} \mathrm{U}$ values below secular equilibrium. The most likely cause of the ${ }^{234} \mathrm{U}$ deficit is posteruption alteration or chemical weathering, which is also supported by a negative relationship between $\delta^{234} \mathrm{U}$ and $\mathrm{Th} / \mathrm{U}$ that indicates $\mathrm{U}$ mobility. Ce/Mo and $\delta^{98} \mathrm{Mo}$ also show some correlation with $\delta^{234} \mathrm{U}$, indicating that alteration may have compromised the Mo isotope system by leading to the preferential loss of heavy isotopes of Mo. However, a subset of samples with anomalously low $\delta^{98}$ Mo and $\delta^{238} \mathrm{U}$ values together with ${ }^{234} \mathrm{U} /{ }^{238} \mathrm{U}$ at secular equilibrium are consistent with incorporation of sediments into the mantle sources of these lavas. 